\title{
ALGUMAS REFLEXÕES SOBRE A NOÇÃO DE SUJ EITO NA TEORIA BAKHTINIANA E NA TEORIA PECHETIANA
}

Adriana Trindade Vargas

\begin{abstract}
RESUMO
Este trabalho busca analisar a constituição do sujeito em duas correntes teóricas distintas: no Círculo de Bakhtin e na Análise de Discurso de linha francesa, cujos principais representantes são: Bakhtin / Voloshinov e Pêcheux / Orlandi. A autora busca saber como é o processo de constituição e o lugar ocupado por esse sujeito nesses campos teóricos tão importantes para os estudos da linguagem.
\end{abstract}

PALAVRAS-CHAVE: Bakhtin; Sujeito; Pêcheux.

\section{Introdução}

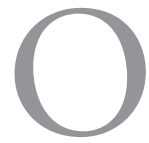

presente artigo tem por objetivo propor uma reflexão sobre a constituição da noção de sujeito, assim como o lugar ocupado por ele na visão bakhtiniana e pechetiana, através de relações estabelecidas entre os respectivos campos teóricos. A escolha pelas referidas teorias apoia-se no dizer:

Bakhtin e seu Círculo têm já um lugar consolidado na história do pensamento linguístico. Apesar de todos os conhecidos percalços de sua trajetória, deixaram uma densa e rica contribuição de natureza filosófica que veio se somar às muitas outras que têm tentado, ao longo dos milênios, apreender o Ser da linguagem. (FARACO, 2010, p. 9) 
Esta pesquisa teórica tem como ponto inicial um estudo breve sobre a importância/não importância, lugar ocupado/não ocupado do/pelo sujeito nas correntes teóricas anteriores ao Círculo de Bakhtin e à análise de discurso de linha francesa. Em seguida, passa a investigar o processo de constituição desse sujeito, assim como o lugar ocupado por ele na perspectiva teórica de Bakhtin/ Voloshinov e de Pêcheux/Orlandi. E finalmente chega às formulaçóes de como esse elemento sujeito aparece nesse "movimento inquietante" denominado processo da linguagem nas respectivas teorias filiadas ao materialismo histórico.

\section{Correntes teóricas anteriores ao círculo de bakhtin e à análise de discurso}

Nosso ponto de partida no presente texto é a fundação da Linguística Moderna, dentre outras variações possíveis. Ferdinand de Saussure, no século $\mathrm{XX}$, nos instigou a muitas reflexóes e discussóes acerca de suas ideias em relação à linguagem. Sua teoria, apesar de sofrer muitas críticas, é considerada como base para qualquer estudo relacionado à linguagem pelos grandes teóri$\cos \mathrm{da}$ área. Mesmo Saussure tendo sido o fundador da Linguística e uma referência aos estudos da linguagem, ele considerou apenas uma parte do processo da linguagem nos seus estudos, a língua.

Em Saussure, a linguagem é definida como um sistema estabelecido ganhando a sua forma dicotômica: langue/parole, sendo que a língua é concebida como um sistema abstrato de regras, social, essencial, e a fala como uso dessas regras, individual e acessória. Nessa concepção teórica, a linguagem é heterogênea (língua/fala) e a língua é homogênea (um sistema de signos linguísticos). Como mencionado acima, Saussure voltou-se para as questóes relacionadas à língua e a definiu como objeto da linguística. Para ele, a língua é um sistema abstrato voltando-se a si, para si, para seu interior, excluindo todas as questóes exteriores. $\mathrm{Na}$ análise saussuriana, não interessa a língua no seu uso, o que interessa é a língua na sua forma, como ela é organizada e as relaçóes estabelecidas no sistema. Saussure não considera o sujeito na sua teoria. O sujeito não tem importância nem ganha um lugar na teoria saussuriana. Os teóricos que surgiram nesse tempo e seguiram a teoria saussuriana são chamados de estruturalistas e o olhar desses estudiosos voltou-se para os estudos fonéticos e morfológicos nos quais a palavra era a unidade de análise. 
Outra linha teórica que surgiu, mas com a mesma concepção de linguagem (totalmente dominada por um falante/ouvinte ideal), foi a gerativista, que teve como fundador Chomsky, na década de 50. Esse teórico centrou-se nos estudos da sintaxe e na sua análise linguística, interessado pela competência, não pelo desempenho individual. Assim o sujeito ainda não tem um lugar marcado nos estudos da linguagem. "Enquanto não há espaço para a semântica, para as questóes ligadas à significação, o sujeito continua ausente" (PETRI, 2004, p. 67). Em Labov, entre os anos 60 e 70, o interesse foi diferente; ele levantou questóes acerca desse falante/ouvinte ideal que domina uma língua que é abstrata e homogênea, observando como o componente social pode produzir diferenças no momento do uso da língua. A partir daí, inicia-se um questionamento sobre a definição de homogeneidade da língua. Logo, Labov admite que a língua é heterogênea, com algumas observações. Na sua teoria, ele diz que por trás da língua há uma organização específica, na qual o estatuto social dos falantes de um determinado grupo e as variantes linguísticas que eles utilizam são correlacionáveis, têm um modo sistemático de existir. $\mathrm{O}$ sujeito continua sem importância e sem um lugar nos estudos da linguagem.

Então, surge Benveniste com a sua teoria dando o devido lugar ao sujeito, tăo excluído por Saussure e os demais teóricos. Benveniste contribui para que esse sujeito ocupe o seu lugar com a teoria da subjetividade da linguagem, em que encontra um sujeito que se apropria da língua e a atualiza. Essa corrente teórica deu importância às questóes referentes ao sujeito e à significação, abrindo espaço para o movimento dos sentidos na concepção de linguagem e considerando o sujeito como elemento essencial. Em Benveniste, o sujeito é o centro, ele é o criador de enunciados no funcionamento da língua, mas ele existe porque há uma relaçáo de um "eu" com um "tu". A partir dessa visão teórica, a linguagem é entendida como representação do mundo, por ser compreendida como responsável pela constituição do sujeito. Apesar de Benveniste contribuir com uma teoria inovadora da subjetividade para o desenvolvimento dos estudos da linguagem, sua concepção de sujeito como ser onipotente, centrado, fonte do seu dizer é bastante questionada pelos teóricos.

Nesse tempo, surge também a Linguística Textual, cujo objeto de estudo é o texto. Essa corrente teórica propóe uma análise mais ampla saindo do limite da frase. Entretanto, não se relaciona com elementos da exterioridade, não dando importância nem lugar ao sujeito. 


\section{Análise de discurso de linha francesa}

Nas décadas de 1960 e 1970, é fundada a Análise de Discurso na França por Michel Pêcheux; à análise de discurso, interessa o discurso.

Segundo Orlandi (2007) na análise de discurso, compreende-se a língua fazendo sentido, enquanto trabalho simbólico, parte do trabalho social geral, constitutivo do homem e da sua história. Nessa teoria discursiva, a linguagem é compreendida como mediação entre o homem e a realidade natural e social. Desse modo, a concepção de língua no pensamento pechetiano não é enquanto um sistema abstrato (Saussure), mas de língua funcionando no mundo, em movimento, com homens falando, produzindo sentidos enquanto parte de suas vidas. Essa nova visão de linguagem (que a relaciona com a sua exterioridade) levanta questóes à Linguística, interpelando-a pela historicidade que ela náo considera, e às Ciências Sociais, interrogando a transparência da linguagem sobre a qual elas se assentam. Os estudos discursivos "visam pensar o sentido dimensionado no tempo e no espaço das práticas do homem, descentrando a noçáo de sujeito e relativizando a autonomia do objeto da Linguística" (ORLANDI, 2007, p. 16). A constituição do sujeito na análise discursiva se realiza quando o indivíduo é interpelado em sujeito pela ideologia, só assim é possível se produzir o dizer. A partir disso, observa-se que, sem ideologia, o sujeito não se constitui. Na teoria discursiva, a ideia de sujeito que se considera é que ele se constitui porque é atravessado pela linguagem e pela história, no modo imaginário, e só tem acesso a parte do que diz. Esse sujeito da análise de discurso é materialmente dividido desde sua constituição:

ele é sujeito de e é sujeito à. Ele é sujeito à língua e à história, pois para se constituir, para (se) produzir sentidos, ele é afetado por elas. Ele é assim determinado, pois se não sofrer os efeitos do simbólico, ou seja, se ele não se submeter à língua e à história, ele não se constitui, ele não fala, não produz sentidos (ORLANDI, 2007, p. 49)

O sujeito na análise de discurso tem fundamental importância (se ele não se constituir, não há dizer) e ele ocupa um lugar e posição de sujeito. $\mathrm{O}$ sujeito fala de posiçốes sociais diferentes. 
Uma outra questão em relação à constituição do sujeito na análise de discurso, conforme Orlandi (2007), é a forma-sujeito histórica que corresponde à da sociedade atual que demonstra a contradição: consiste em um sujeito que ao mesmo tempo é livre e é submisso (é livre para dizer mas submisso à língua para sabê-la). Isso chama- se assujeitamento na análise de discurso. Através da noção de determinação, o sujeito gramatical cria um ideal de completude, participando do imaginário de um sujeito mestre de suas palavras: ele determina o que diz. Esse é o sujeito-de-direito/jurídico, o da modernidade. O sujeito-de- direito não é um indivíduo, mas um efeito de uma estrutura social bem determinada: a sociedade capitalista. Ainda de acordo com a mesma autora (2007), na teoria pechetiana, ao dizer nos significamos e significamos o próprio mundo. $\mathrm{Na}$ análise de discurso, o sentido é história; o sujeito do discurso se faz (se significa na/pela história). Ao analisar a constituição do sujeito na teoria discursiva, observa-se que o sujeito é dotado de inconsciente e atravessado pela ideologia, sua presença é fundamental na teoria do discurso, sua constituição está ligada à constituição do sentido no discurso.

\section{Círculo de Bakhtin}

Ainda nessa segunda metade do século XX, em meio à efervescência das reflexôes sobre os estudos da linguagem, é reacendida uma teoria, a teoria dialógica, recém-chegada ao Ocidente, traduzida para o francês, com ascendência russa, cujos principais representantes são Bakhtin/Voloshinov. Esses dois teóricos eram membros do Círculo de Bakhtin. Bakhtin diz que o discurso nasce de uma situação pragmática, extraverbal, contextual, historial, e que continua a ligação com essa situação para poder manter sua significação.

Conforme Bakhtin, a língua tem a propriedade de ser dialógica. As relações dialógicas não são entendidas como um diálogo face a face; ao contrário, todos os enunciados no processo de comunicação, independentemente de sua dimensão, são dialógicos. O dialogismo é composto pelas relaçôes de sentido que se estabelecem entre dois enunciados. E é justamente a partir dessa interação verbal na relaçấo com o outro que o sujeito é constituído socialmente. No pensamento bakhtiniano, o sujeito se constitui no interior da heteroglossia e de sua dialogização. O sujeito se constitui através de uma realidade em que se perpassam vozes sociais constantemente em múltiplas inter-relaçôes dialógicas. 
E é nesse movimento de vozes sociais, através da compreensão responsiva (processo de construção de sentido em que o interlocutor tem participação ativa), que o sujeito ocupa um lugar na teoria do Círculo de Bakhtin. Como diz Faraco:

Como a realidade linguístico-social é heterogênea, nenhum sujeito absorve uma só voz social, mas sempre muitas vozes. Assim, ele não é entendido como um ente verbalmente uno, mas como um agitado balaio de vozes sociais e seus inúmeros encontros e entrechoques. O mundo interior é uma arena povoada de vozes sociais em suas múltiplas relaçóes de consonância e dissonância; e em permanente movimento, já que a interação socioideológica é um contínuo devir. (FARACO, 2010, p. 84)

Na teoria bakhtiniana, a consciência no indivíduo toma forma e existência nos signos criados por um grupo social no processo de sua interação social. E é nos signos que a consciência individual se alimenta; é deles que deriva seu crescimento, reflete sua lógica e leis - lógica essa a da interação socioideológica, ou seja, lógica das relaçóes dialógicas, do plurilinguismo dialogizado. "É esta dinâmica social que, internalizada, desencadeia o moto contínuo da atividade psíquica” (FARACO, 2010, p. 85). Na concepção do Círculo, a consciência é social de ponta a ponta, embora o Grupo não negue a singularidade e, desde os primeiros textos de Bakhtin, insiste em afirmar que cada ser humano ocupa um lugar único e insubstituível, na medida em que cada um responde às suas condições objetivas de modo diferente de qualquer outro. Os membros do Círculo de Bakhtin buscaram uma compreensão da pessoa humana na perspectiva de suas relaçóes sociais e como um ente interiormente múltiplo e heterogêneo; preocuparam-se também em manter um espaço teórico significativo para a singularidade, anulando qualquer determinismo absoluto. Para o Círculo, o sujeito é social de ponta a ponta, sendo que a origem do alimento e da lógica da consciência é externa à consciência; e singular de ponta a ponta porque os modos como cada consciência responde às suas condiçóes objetivas são sempre singulares, já que cada um é um evento único do Ser. "O sujeito tem, desse modo, a possibilidade de singularizar-se e de singularizar seu dis- 
curso não por meio da atualização das virtualidades de um sistema gramatical [...], mas na interação viva com as vozes sociais" (FARACO, 2010, p. 87).

\section{Distanciamentos e aproximações entre as duas teorias: bakhti- niana e pechetiana}

Conforme Orlandi (2001), a essa concepção de constituiçãao do elemento sujeito dialógico, da teoria do Círculo de Bakhtin, é que parece ir a crítica de Pêcheux a Voloshinov, a que não vê na língua sua autonomia relativa, a que não lhe reconhece sua ordem própria. Ainda sobre a constituição do elemento sujeito dialógico, há um outro aspecto, aquele que nos permite ver aí um social não apreendido pela história. Decorre disso o sociologismo, daí o sujeito psicológico (o das intençôes) e, assim, a interação como fato psicossocial.

A noção de Discurso com a compreensão do que seja a historicidade (interdiscurso) na relação da língua com os sentidos (não enquanto conteúdo, mas como "relação a") permite pensar o sujeito não psicológico, mas afetado pela ideologia e pelo inconsciente conjuntamente.

Segundo Indursky (2000), embora sejam claras as distinções em relação à constituiçáo do elemento sujeito entre a teoria dialógica e a da análise de discurso (de linha francesa), podemos falar em aproximaçōes entre as teorias bakhtiniana e pechetiana quando se trata de interlocução discursiva e heterogeneidade do discurso, que é a forma que a dialogia assumiu no âmbito dos estudos discursivos.

Já em relação ao sujeito, o interesse deste trabalho, em Bakhtin e em Pêcheux, arriscamos dizer que estão sob o mesmo olhar teórico quando se trata de um sujeito descentralizado que se constitui a partir de elementos externos à língua, não sendo fonte do seu dizer.

Destarte, tem-se o sujeito bakhtiniano e pechetiano marcado em sua posição e em seu lugar, com algumas aproximaçōes e muitos distanciamentos.

\section{Referências}

BAKHTIN, M./ Voloshinov, V. N. Marxismo e filosofia da linguagem. Tradução Michel Lahud e Yara Frateschi Vieira. 3ª ed. São Paulo: Hucitec, 1986.

FARACO, Carlos. Linguagem e Diálogo. As idéias lingüísticas do Círculo de 
Bakhtin. São Paulo: Parábola Editorial, 2010.

INDURSKY, Freda. Reflexões sobre a linguagem: de Bakhtin à Análise de Discurso. In: Artigo publicado na Revista Linguas e Instrumentos Linguisticos. Dez.1999/ Junho 2000 n 4/5 Campinas: Pontes, 2000.

ORLANDI, Eni P. Análise de discurso. Princípios e procedimentos. Campinas: Editora Pontes, 2007.

. M. Bakhtin em M. Pêcheux: no risco do conteudismo. Rio de Janeiro: Editora Vozes, 1996. In: Beth Brait (org) Dialogismo e construção do sentido. São Paulo: Editora Unicamp, 2001.

PÊCHEUX, M. Análise de Discurso. Textos selecionados: Eni Orlandi. $3^{\text {a }}$ ed. Campinas: Pontes, 2012

PETRI, Verli. Algumas reflexóes sobre o sujeito nos estudos da linguagem. In: Linguas e Instrumentos Linguisticos, n. 13/14. Campinas, São Paulo: Pontes, 2004, p. 65-74.

\title{
SOME REFLECTIONS ON THE NOTION OF SUBJECT IN BAKHTIN'S AND PÊCHEUX'S THEORIES
}

\begin{abstract}
This paper aims to analyze the constitution of the subject in two different theoretical perspectives: Bakhtin Circle and French Discourse Analysis, whose main representatives are Bakhtin/Voloshinov and Pêcheux/ Orlandi. The author seeks to understand the process of constitution and the "place" occupied by the subject in these theoretical fields, which are so important to the study of language.
\end{abstract}

KEYWORDS: Bakhtin; Subject; Pêcheux.

Recebido em: 30/08/2013

Aprovado em: 20/12/2013 